\title{
A COMPARISON OF THE UREA NITROGEN CONTENT OF CUTANEOUS AND VENOUS BLOOD BY MICRO GASOMETRIC ANALYSIS
}

\author{
By CHRISTOPHER JOHNSTON \\ (From the Hospital of the Rockefeller Institute for Medical Research, New York)
}

(Received for publication April 8, 1930)

Svensgaard (1) using the micro urea method of Rehberg (2) compared the urea concentrations in blood from the arm vein with that of cutaneous blood from the lobe of the ear. In 29 of 32 analyses of the blood of normal fasting subjects she found the urea of the capillary blood higher than that of the venous blood. The average difference was 10 per cent of the venous urea content, but individual differences were as high as 24 per cent. Such results, if confirmed, would indicate that the use of cutaneous blood from the ear for analysis could introduce errors up to 24 per cent in tests of renal function, such as the blood urea clearance used in this clinic $(3,4,5)$, which depend upon blood urea determinations.

It was therefore thought advisable to make a series of determinations of the urea content of samples of cutaneous and venous blood taken simultaneously and both analyzed by the Van Slyke micro gasometric method (6) in order to ascertain whether the variations found by Svensgaard could be confirmed. A report of the analyses is given in this paper.

\section{METHODS}

Into each of two small tubes (10 $\mathrm{mm}$. inner diameter and $50 \mathrm{~mm}$. in length) a little powdered heparin was introduced. The tubes were then rotated horizontally until the heparin was evenly distributed, and were then inverted so that only the finely powdered heparin which clung to the walls of the tube remained. After preliminary rubbing to produce hyperemia, the lobe of the ear was punctured deeply enough to insure a free flow with only slight pressure, and sufficient blood was collected in one tube. From time to time during the collection the puncture wound was wiped clean so that only fresh blood would be obtained. Vena puncture was done immediately afterward, either with or without stasis. The samples were taken immediately to the laboratory and $0.2 \mathrm{cc}$. portions measured 
TABLE 1

Comparison of the urea nitrogen content of cutaneous and venous blood

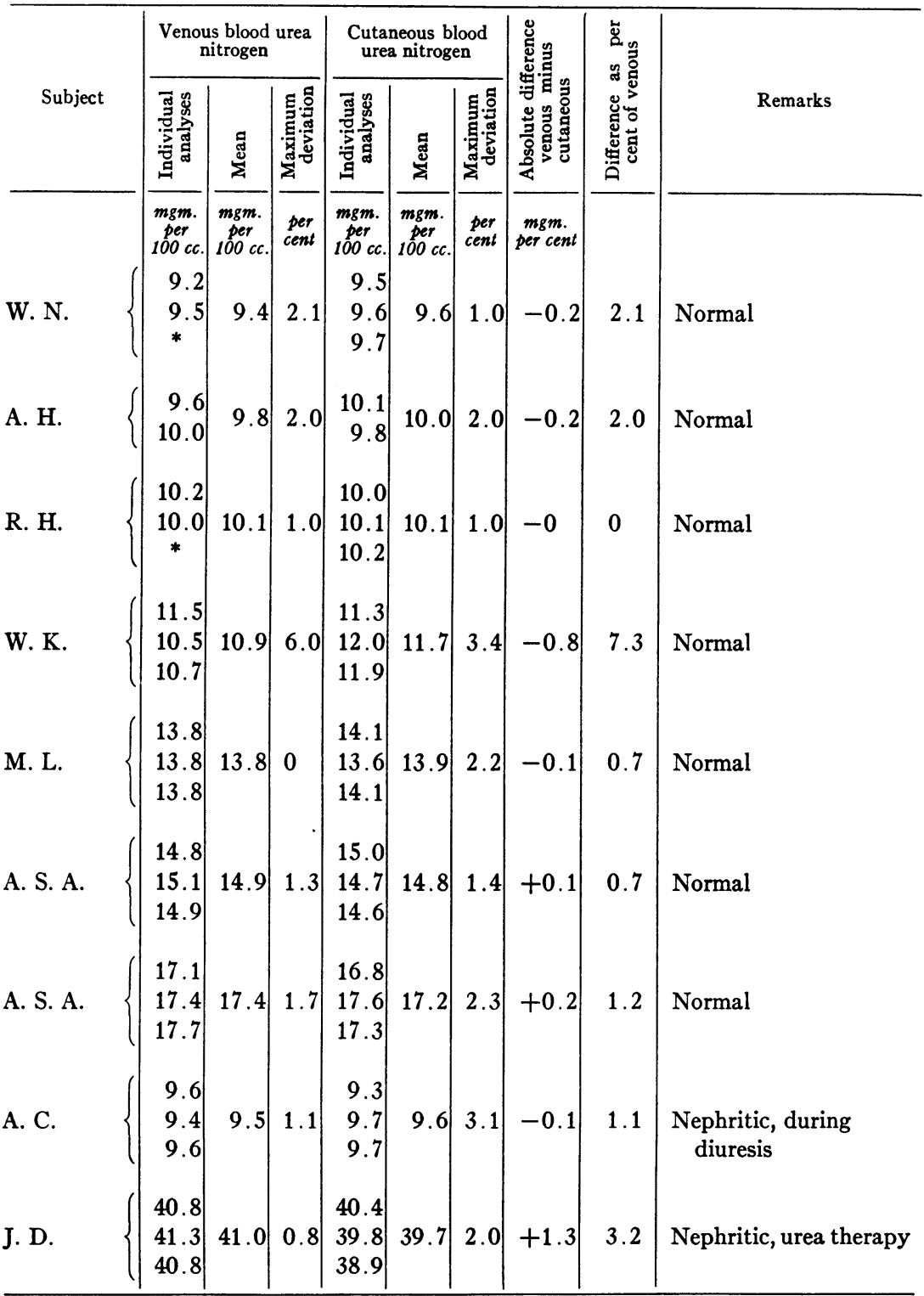

Average of all venous bloods $42.4 \mathrm{mgm}$. per cent. Average of all cutaneous bloods $42.4 \mathrm{mgm}$. per cent.

* Discarded because of gross error. 
TABLE 1-Concluded



into tubes containing $1 \mathrm{cc}$. of $0.02 \mathrm{~N}$ lactic acid as described by Van Slyke. As analyses were made in triplicate, three accurately calibrated pipettes were used. After taking the three samples of blood from one source they were washed and thoroughly dried before using again. After addition to lactic acid, the samples stood at room temperature. As each analysis takes 15 minutes, and as at least two blank determinations were made with each experiment, the last sample stood approximately 2 hours before analysis, but it seemed to make no difference.

The method of collecting blood from the ear into a tube rather than by drawing directly into a pipette was chosen because it is easier, and measurement of the 0.2 cc. samples can be made more comfortably and hence with greater accuracy in the laboratory. There is no trouble from clotting.

Bleedings were done between one and two hours after lunch, except in three experiments, which were done about the same length of time after breakfast. No attempt was made to control diet.

\section{RESULTS}

Inspection of table 1 shows that the gasometric method, using $\mathbf{0 . 2}$ cc. of whole blood, gives results of sufficient accuracy to demonstrate 
any essential difference in the concentration of urea nitrogen between cutaneous and venous blood. Occasionally, through faulty technic, one gets a reading that is obviously incorrect and has to be discarded. This happened but four times in this series of 72 analyses. In the case of subject W. K., it is likely that one of the stopcocks was leaking slightly, which led to the introduction of an error much larger than usual. For this reason the experiment should probably be discarded but it is included here for the sake of completeness. No experiments have been omitted from the table.

Excluding the observation in question, five of the remaining twelve sets of analyses showed a higher concentration in cutaneous blood (average 1.6 per cent), five showed higher concentration in venous blood (average 1.2 per cent), and two showed no difference. The average concentration in the twelve samples of both venous and cutaneous blood is $45.0 \mathrm{mgm}$. per cent urea nitrogen. The maximum difference in any one experiment was only 3.2 per cent.

\section{DISCUSSION}

Marshall and Davis (7) in a study of the distribution of urea in the body concluded that "the urea content of all organs and tissues is approximately uniform, and approximately equal to that of blood, both in normal conditions, and when there is an abnormally large amount of urea present." Furthermore "when urea in solution is injected intravenously, it diffuses to all parts of the body almost instantly, the diffusion being complete in a few minutes." GadAndresen (8) came to essentially the same conclusions with regard to equilibrium between tissues and blood, and in addition found that the distribution coefficient between body secretions and blood plasma was unity, with the exception of sweat and tears, in which the concentration of urea was higher than in the plasma. He found, however, that plasma contained more urea than the erythrocytes, the distribution coefficient being between 0.72 and 0.82 . Both Marshall and Davis and Gad-Andresen found that fat is an exception to the general rule in that it is relatively poor in urea. The experiments of Bollman, Mann, and Magath (9) seem definitely to have established that urea formation is a function of the liver only. If equilibrium exists between blood and tissues, one would expect to find no difference in the concentration of urea between venous and cutaneous blood. 
So far, no explanations have been found to account for the apparent differences noted by Svensgaard. The fact that the mean error of her tests was $\pm 1 \mathrm{mgm}$. urea $(0.47 \mathrm{mgm}$. urea $\mathrm{N})$ might have contributed some, but the average difference noted was much greater than this. Returning again to her observations on normal subjects, the concentration of urea in capillary blood varied between 4 and 22 per cent higher than in venous blood. After administration of urea, or of protein the differences were from 1 to 7 per cent. In seven cases of icterus the variation was from 2 to 23 per cent, in five cases of nephritis from 1 to 13 per cent, and in 8 of 9 diabetics from 2.2 to 24 per cent.

\section{SUMMARY AND CONCLUSIONS}

1. The concentration of urea nitrogen in the blood from ear puncture has been compared with that from the vein in 13 experiments on 6 normal and 6 nephritic subjects, without regard to food intake.

2. No difference between venous and cutaneous blood exceeding the limit of experimental error was found to exist.

\section{BIBLIOGRAPHY}

1. Svensgaard, E., Biochem. J., 1927, xxi, 522. Studies of the Urea Content of Capillary and Venous Blood.

2. Rehberg, P. B., Biochem, J., 1925, xix, 278. The Determination of Urea in $0.1 \mathrm{cc}$. of Blood by Microtitration.

3. Möller, E., McIntosh, J. F., and Van Slyke, D. D., J. Clin. Invest., 1928, vi, 427. Studies of Urea Excretion. II. Relationship Between Urine Volume and the Rate of Urea Excretion by Normal Adults.

4. McIntosh, J. F., Möller, E., and Van Slyke, D. D., J. Clin. Invest., 1928, vi, 467. Studies of Urea Excretion. III. The Influence of Body Size on Urea Output.

5. Möller, E., McIntosh, J. F., and Van Slyke, D. D., J. Clin. Invest., 1928, vi, 485. Studies of Urea Excretion. IV. Relationship Between Urine Volume and Rate of Urea Excretion by Patients with Bright's Disease.

6. Van Slyke, D. D., J. Biol. Chem., 1927, lxxiii, 695. Determination of Urea by Gasometric Measurement of the Carbon Dioxide Formed by the Action of Urease.

7. Marshall, E. K., Jr., and Davis, D. M., J. Biol. Chem., 1914, xviii, 53 . Urea: Its Distribution in and Elimination from the Body.

8. Gad-Andresen, K. L., Biochem. Ztschr., 1921, cxvi, 266. Die Verteilung des Harnstoffes im Organismus.

9. Bollman, J. L., Mann, F. C., and Magath, T. B., Am. J. Physiol., 1924, lxix, 371. Studies on the Physiology of the Liver. VIII. Effect of Total Removal of the Liver on the Formation of Urea. 